\title{
Clinical benefit of high-volume hemofiltration in severe burn injury: is it removing bad humors or actually avoiding hypervolemia?
}

\author{
Patrick M. Honore ${ }^{1 *}$, David De Bels ${ }^{1}$, Thierry Preseau ${ }^{2}$, Sebastien Redant ${ }^{1}$, Rachid Attou ${ }^{1}$, Andrea Gallerani ${ }^{1}$ \\ and Herbert D. Spapen ${ }^{3}$
}

See related research by You et al., https://ccforum.biomedcentral.com/articles/10.1186/s13054-018-2095-9

Recently, You et al. [1] reported that early application of high-volume hemofiltration (HVHF) reduced the incidence of sepsis, septic shock, and organ failure in patients with burns $\geq 50 \%$ total burn surface area (TBSA) and improved survival of patients with burns $\geq 80 \%$ TBSA. The benefit of HVHF was attributed to hemofiltration/adsorption of proinflammatory cytokines and other sepsis-related mediators and recovery of the patients' immune status [1]. However, HVHF as adjuvant therapy for sepsis has previously been shown to have no significant impact on hemodynamics, short-term morbidity and mortality, and cytokine clearance $[2,3]$. The results from You et al. are more remarkable because HVHF was performed with a less adsorptive dialysis membrane and a relatively low prescribed effluent rate $[2,3]$. Moreover, $70-100 \%$ of the replacement solution was administered in predilution, which makes convective mediator removal less effective as compared to full postdilution [2,3].

Cytokine levels fell most during the 3-day HVHF treatment. Thereafter, levels followed a rather "flat" course in both treatment groups without surges reflecting the occurrence of sepsis or septic shock. No data are available regarding the origin (pulmonary, catheter, etc.) or type (Gram-negative or Gram-positive, fungal) of sepsis, all of which may determine cytokine and mediator fluxes. It is also questionable that a lower procalcitonin (PCT) level in the HVHF group represents less inflammation. PCT (molecular weight $13 \mathrm{kDa}$ ) indeed is easily removed by any form of convective continuous renal replacement

\footnotetext{
* Correspondence: Patrick.Honore@CHU-Brugmann.be

${ }^{1}$ ICU Department, Centre Hospitalier Universitaire Brugmann—Brugmann

University Hospital, Place Van Gehuchtenplein,4, 1020 Brussels, Belgium

Full list of author information is available at the end of the article
}

therapy, thereby losing sensitivity to detect or assess inflammatory processes [4].

The most striking finding is the rapid reversal of shock as mirrored by less vasopressor dependency in the HVHFtreated patients. Liberating patients from vasopressor treatment is of utmost importance in burn patients, not only as an indicator of hemodynamic stabilization but particularly to avoid graft ischemia, rejection, and surinfection [3]. The authors associate this "acute" effect with HVHF-induced immune-inflammatory modulation [1]. Of note is that no information is provided on fluid administration and evolution of fluid balances. Patients with severe burn injury receive massive fluid loads during the first days of treatment. Early de-resuscitation (i.e., evacuation of excess fluid aiming at zero fluid balance around day 3 of treatment) is a crucial factor to improve morbidity and perhaps mortality in critically ill and injured patients [5]. HVHF may thus have acted as an excellent method to rapidly reach de-resuscitation targets.

\section{Abbreviations \\ HVHF: High-volume hemofiltration; PCT: Procalcitonin; TBSA: Total burn surface area}

\section{Acknowledgements \\ None.}

Funding

None.

Availability of data and materials Not applicable. 


\section{Authors' contributions}

$\mathrm{PMH}$ and HDS designed the manuscript. All authors participated in drafting and reviewing. All authors read and approved the final version of the manuscript.

\section{Ethics approval and consent to participate}

Not applicable.

\section{Consent for publication}

Not applicable.

\section{Competing interests}

The authors declare that they have no competing interests.

\section{Publisher's Note}

Springer Nature remains neutral with regard to jurisdictional claims in published maps and institutional affiliations.

\section{Author details}

'ICU Department, Centre Hospitalier Universitaire Brugmann-Brugmann University Hospital, Place Van Gehuchtenplein,4, 1020 Brussels, Belgium.

2Emergency Department, Centre Hospitalier Universitaire Brugmann, Brussels, Belgium. ${ }^{3}$ Universitair Ziekenhuis Brussel, VUB University, Brussels, Belgium.

Received: 14 September 2018 Accepted: 12 October 2018

Published online: 01 November 2018

\section{References}

1. You B, Zhang YL, Luo GX, et al. Early application of continuous high-volume haemofiltration can reduce sepsis and improve the prognosis of patients with severe burns. Crit Care. 2018;22:173.

2. Clark E, Molnar AO, Joannes-Boyau O, Honoré PM, Sikora L, Bagshaw SM High-volume hemofiltration for septic acute kidney injury: a systematic review and meta-analysis. Crit Care. 2014;18:R7.

3. Chung KK, Lundy JB, Matson JR, et al. Continuous venovenous hemofiltration in severely burned patients with acute kidney injury: a cohort study. Crit Care. 2009;13:R62.

4. Honore PM, Spapen HD. The struggle to differentiate inflammation from infection in severely burned patients: time to send better biomarkers into the arena? Crit Care. 2016;20:13.

5. Silversides JA, Fitzgerald E, Manickavasagam US, et al. Deresuscitation of patients with iatrogenic fluid overload is associated with reduced mortality in critical illness. Crit Care Med. 2018. https://doi.org/10.1097/CCM.0000000000003276 [Epub ahead of print] 